\title{
Making Sense of Nonsense: Writing advice from Lewis Carroll and the "Jabberwocky"
} COMMUNICATION CORNER No. 42

\author{
by Philip Yaffe
}

\section{Editor's Introduction}

Each "Communication Corner" essay is self-contained; however, they build on each other. For best results, before reading this essay and doing the exercise, go to the first essay "How an Ugly Duckling Became a Swan," then read each succeeding essay.

Lewis Carroll is justifiably world-renowned for his whimsical and sometime apparently ridiculously incongruous works of fiction, e.g. Alice in Wonderland. However, underneath the charming facade, there is very good advice which, once uncovered, can help expository (nonfiction) writers significantly improve their work. 


\title{
Making Sense of Nonsense: Writing advice from Lewis Carroll and the "Jabberwocky"
} COMMUNICATION CORNER No. 42

\author{
by Philip Yaffe
}

The absolute, unalterable, incontestable hallmark of a good expository (non-fiction) text is its clarity. Whatever other attributes it may have, if it isn't clear, it isn't good. Likewise, if it isn't good, it isn't clear.

Clarity being the prime criterion, what possible relationship could there be between the absolute nonsense of Lewis Carroll's poem "Jabberwocky" (in Alice's Adventures in Wonderland) and good expository writing? A great deal, actually, because "Jabberwocky" is not absolute nonsense. And that's its great appeal.

If you have ever read the book or seen the Disney film, you know this poem. But let's refresh our memories by looking at just the first paragraph.

"Twas brillig, and the slithy toves

Did gyre and gimble in the wabe;

All mimsy were the borogoves,

And the mome raths outgrabe."

Far from being nonsense, each line is meticulously crafted to give the impression that it is saying something serious. In Alice's own words, "It seems to fill my head with ideas-only I don't know exactly what they are."

This is exactly what a good expository text should do. First, present an idea, which of course will be fuzzy until you take the second step, which is to clearly explain it.

Too many expository texts fail to follow this simple two-step procedure. Instead, they mix an idea together with details, without clearly separating them. Or they give all the supporting details first, with kind of a surprise ending: "Hey, here's what all of this really means!"

Both approaches are dramatically incorrect.

Not clearly distinguishing key ideas from details means the key ideas get lost in the details. People are not quite certain what they are supposed to retain from the text, so they retain very little. 
Saving the key idea for the end is probably worse. Readers must wade through an ocean of details without understanding their significance, so many will give up before they get to the end. Those that do make it to the end are challenged to go back through the text to better understand the conclusion, which most are unlikely to do.

So the best approach to most expository texts is:

- Clearly state an idea

- Then clearly explain it

Does the "Jabberwocky" follow this procedure? Yes, but in its own inimitable way.

From the near total nonsense of the first paragraph, it passes to near total understanding in the second paragraph.

"Beware the Jabberwock, my son!

The jaws that bite, the claws that catch!

Beware the Jubjub bird, and shun

The frumious Bandersnatch!"

It continues in this near understanding mode throughout the third, fourth, fifth, and sixth paragraphs. Only to conclude with the near total nonsense of the first paragraph, which by now somehow seems less nonsensical than it did at the beginning.

We shouldn't stretch this analysis too far because Mr. Carroll obviously didn't achieve the number one objective of any expository text-to be perfectly clear. But of course this wasn't his intention. Unfortunately, many expository writers also fail to achieve the objective, because "clear" is a weasel word, i.e. it means different things to different people. What is clear to you may not be clear to me, and vice versa.

The best way to resolve this problem is to give "clear" a functional definition. A kind of recipe we can apply when writing a text. And a test we can apply to evaluate the text when we have finished. And here it is.

In order to be clear, you must do three things:

1. Emphasize what is of primary importance.

2. De-emphasize what is of secondary importance.

3. Eliminate what is of no importance.

In short, $\mathrm{Cl}=\mathrm{EDE}$ 
This is not a perfect solution to the problem of clarity (nothing is), but it comes reasonably close.

First, you identify the key ideas you want to convey and make certain that they are highlighted (primary importance). Second, you explain or defend these key ideas with appropriate supporting information (secondary importance). Finally, you eliminate everything else (no importance). This means rejecting all information that does not support one or more of the key ideas.

As a result, you arrive at a text that is admirably clear, because everything is in its proper place. Your text is also automatically well on the way to being admirably concise because you have gotten rid of everything of no importance. In a first draft, information of no importance can take up as 30 percent of the text, so by eliminating it you have reduced the length by 30 percent.

\section{An Illuminating Anecdote}

It is not commonly known that Lewis Carroll's real name was Charles Lutwidge Dodgson. And in addition to being a superb storyteller, he was also a first-class logician and mathematician.

I discovered this when I was a mathematics student at UCLA (University of California at Los Angeles). As part of my studies, I had to take a class in semantic and symbolic logic. Having been acquainted with Alice in Wonderland only through the Disney cartoon, I was surprised to see a reference to it in the course textbook. Then another one. And another one. And another one. The more references I encountered, the curiouser and curiouser I became. I had to read the book.

The fact is, Alice in Wonderland is heavy with mathematical and logical allusions, if you know where to look. Prof. Dodgson (Carroll) may have included them on purpose, but given who he was, they might have just found their way into the work naturally. In any event, I was intrigued and determined to find them.

One day, I was sitting in front of the university waiting for a bus and reading Alice in Wonderland. A little old lady walked by. A puzzled expression came over her face when she noticed what I was reading. First, she stared at the book, then at the university, then back at the book. Finally she walked away, shaking her head. I don't know what she was thinking, but I am certain it wasn't very flattering, either for me or the university. 


\section{ABOUT THE AUTHOR}

Philip Yaffe was born in Boston, Massachusetts, in 1942 and grew up in Los Angeles, where he graduated from the University of California with a degree in mathematics and physics. In his senior year, he was also editor-in-chief of the Daily Bruin, UCLA's daily student newspaper. He has more than 40 years of experience in journalism and international marketing communication. At various points in his career, he has been a teacher of journalism, a reporter/feature writer with The Wall Street Journal, an account executive with a major international press relations agency, European marketing communication director with two major international companies, and a founding partner of a specialized marketing communication agency in Brussels, Belgium, where he has lived since 1974 . He is the author of more than 30 books, which can be found easily in Amazon Kindle.

DOI: $10.1145 / 3506858$ 